\title{
THE UTILITY OF 4-(2-THIENYL)PYRIDINES AS A DERIVATIZATION REAGENT FOR HPLC AND CE
}

\author{
Riichiro NaKaJIMA, Eiji NaKamoto, Hiroki KamiUCHI, Youko UEDA, Sus umu \\ OGURA, Takashi TAMURA and Tadashi HARA \\ Faculty of Engineering, Doshisha University, Kamigyo-ku Kyoto, 602, Japan
}

\begin{abstract}
To emphasize the capability of a fluorescent thienylpyridine skeleton, the derivatization of carboxylic acid, aldehyde, ketone, and glycine were examined and applied to the following determinations: glycine with 5-(4-pyridyl)-2-thiophenecarbaldehyde using CE, carboxylic acids with 5-(4-pyridyl)-2-thiophenemethanol or 4(5-diazomethyl-2-thienyl)pyridine using HPLC, carboxylic acids with 1-(2-ammonioethyl)-4-(2-thienyl)pyridinium dibromide using CE, and aldehydes and ketones with 4(2-thienyl)pyridinium acetohydrazide chloride.
\end{abstract}

Key words thienylpyridine, quaternary pyridinium salt, fluorescent Girard reagent

Recently, we have reported that a thienylpyridine skeleton is a new fluorophore, which exhibits two different spectra in acidic and basic solutions, respectively[1]. The compounds including this skeleton are classified into two groups i.e. non-ionic compounds and quaternary pyridinium salts. The above-mentioned spectra were observed in the former compounds and the latter compounds in both acidic and basic solutions exhibited the same spectra as in the former compounds in acidic solution. To extend the capabilities of this skeleton, the following compounds were prepared and used for the determination of carboxvlic acid. aldehvde, etc. using HPLC nr CE(capillary zone electrophoresis): 5-(4-pyridyl)-2-thiophenecarbaldehyde(1), 5-(4-pyridyl)-2thiophenemethanol(2), 4-(5-diazomethyl-2-thienyl)pyridine(3), 1-(2-ammonioethyl)-4-(2-thienyl)pyridinium dibromide (4), and 4-(2-thienyl)pyridinium acetohydrazide chloride(5). Detection limits and linear ranges for most of analytes were superior to those reported previously[2-3].

\section{Experimental}

The instruments were same as those previously used[4,5]. Reagents 1[6], 2[4], 3[7], and 4[5] were prepared by the methods described previously as outlined in Scheme 1. 1-Hexyl-4-(2thienyl)pyridinium bromide $(\mathbf{1 0})$ was prepared by a method similar to that for preparation of 4 .

Preparation of 5 . 1 - (Ethoxy carbony lmethy I) - 4-(2-thienyI) pyridinium chIoride( 9 ): A mixture of 4-(2-thienyl)pyridine $(7)[1](0.77 \mathrm{~g}, 4.8 \mathrm{mmol})$ and ethyl chloroacetate $(0.61 \mathrm{~g}, 5.0$ mmol) was refluxed in ethanol $(1.2 \mathrm{ml})$ for $2 \mathrm{~h}$. After cooling a precipitate was separated and recrystallized from ethanol-concd hydrochloric acid(60:1 v/v) to give light yellow needles 9 in a $52 \%$ yield $(0.71 \mathrm{~g})$. Mp $225.5-226.5^{\circ} \mathrm{C}($ decomp $)$. Found: $\mathrm{C}, 54.98 ; \mathrm{H}, 4.94 ; \mathrm{N} 4.97 \% ;(\mathrm{M}-\mathrm{Cl})^{+}$, 248 (SIMS, in a glycerol matrix). Calcd for $\mathrm{C}_{13} \mathrm{H}_{14} \mathrm{ClNO}_{2} \mathrm{~S}: \mathrm{C}, 55.02 ; \mathrm{H}, 4.97 ; \mathrm{N}, 4.94 \% ; \mathrm{M}$, 283. ${ }^{1} \mathrm{H}$ NMR $\left(400 \mathrm{MHz}, \mathrm{D}_{2} \mathrm{O}\right) \delta=1.39\left(3 \mathrm{H}, \mathrm{t}, J=7.1 \mathrm{~Hz}, \mathrm{CH}_{3}\right), 4.42\left(2 \mathrm{H}, \mathrm{q}, J=7.1 \mathrm{~Hz}, \mathrm{CH}_{2}\right), 5.49$ $\left(2 \mathrm{H}, \mathrm{s}, \mathrm{CH}_{2}\right), 7.28(1 \mathrm{H}, \mathrm{dd}, \mathrm{H}-4$ in thiophene ring $), 7.91-7.92(2 \mathrm{H}, \mathrm{m}, \mathrm{H}-3$ and $\mathrm{H}-5$ in thiophene ring), $8.07(2 \mathrm{H}, \mathrm{d}, J=7.1 \mathrm{~Hz}, \mathrm{H}-3$ and $\mathrm{H}-5$ in pyridine ring $)$, and $8.60(2 \mathrm{H}, \mathrm{d}, J=7.1 \mathrm{~Hz}, \mathrm{H}-2$ and $\mathrm{H}-6$ in pyridine ring). ${ }^{13} \mathrm{C}$ NMR $(100 \mathrm{MHz}) \delta=15.95(\mathrm{q}), 62.39(\mathrm{t}), 66.69(\mathrm{t}), 124.65(\mathrm{~d}, 2 \mathrm{C})$, 132.93(d), 135.07(d), 137.72(d), 139.27(s), 147.79(d, 2C), 152.69(s), and 170.20(s, C=O).

Reagent 5: A mixture of $9(501.4 \mathrm{mg}, 1.77 \mathrm{mmol})$ and $100 \%$ hydrazine hydrate $(347.6 \mathrm{mg}, 7.0$ mmol) was stirred in ethanol $(12.2 \mathrm{~g})$ at $60^{\circ} \mathrm{C}$ for $1 \mathrm{~h}$ to give a precipitate, a portion of the precipitate $(509.9 \mathrm{mg})$ was dissolved in methanol $(50.4 \mathrm{ml})$, and then concd hydrochloric acid $(9.6 \mathrm{ml})$ was added to afford a precipitate, i.e. white needles 5 as hydrous hydrochloride, in a $22 \%$ yield. Mp 284.5-285. $4^{\circ} \mathrm{C}$. Found: C, 40.63; H, 4.43; N, 12.93\%; $\left(\mathrm{M}-2 \mathrm{HCl}-\mathrm{H}_{2} \mathrm{O}\right)^{+}, 233(\mathrm{SIMS}$, in a glycerol matrix). Calcd for $\mathrm{C}_{11} \mathrm{H}_{12} \mathrm{ClN} 3 \mathrm{OS} \cdot \mathrm{HCl} \cdot \mathrm{H}_{2} \mathrm{O}: \mathrm{C}, 40.75 ; \mathrm{H}, 4.66 ; \mathrm{N}, 12.96 \% ; \mathrm{M}, 323$. ${ }_{\mathrm{H}} \mathrm{NMR}\left(\mathrm{D}_{2} \mathrm{O}\right) \delta=5.56\left(2 \mathrm{H}, \mathrm{s}, \mathrm{CH}_{2}\right), 7.29(1 \mathrm{H}, \mathrm{dd}, J=3.9$ and $5.1 \mathrm{~Hz}, \mathrm{H}-4$ in thiophene ring), $7.93(1 \mathrm{H}, \mathrm{dd}, J=1.1$ and $5.1 \mathrm{~Hz}, \mathrm{H}-5$ in thiophene ring), $7.95(1 \mathrm{H}$, dd, $J=1.1$ and $3.9 \mathrm{~Hz}, \mathrm{H}-3 \mathrm{in}$ thiophene ring), 8.11(2 H, d, $J=7.1 \mathrm{~Hz}, \mathrm{H}-3$ and $\mathrm{H}-5$ in pyridine ring), and $8.63(2 \mathrm{H}, \mathrm{d}, J=7.1 \mathrm{~Hz}$, $\mathrm{H}-2$ and $\mathrm{H}-6$ in pyridine ring), ${ }^{13} \mathrm{C}$ NMR $\delta=61.51\left(\mathrm{t}, \mathrm{CH}_{2}\right), 124.74(\mathrm{~d}, 2 \mathrm{C}), 132.96(\mathrm{~d})$, $135.18(\mathrm{~d}), 137.84(\mathrm{~d}), 139.30(\mathrm{~s}), 147.93(\mathrm{~d}, 2 \mathrm{C}), 152.93(\mathrm{~s})$, and $167.69(\mathrm{~s}, \mathrm{C}=\mathrm{O})$. 


\section{Results and Discussion}

Derivatization reagents 1-5 were prepared from 4-(5-methyl-2-thienyl)pyridine(6) or 7, as outlined in Scheme 1. The structure of 1,2 , and 4-9 was proved by their ${ }^{1} \mathrm{H}$ and ${ }^{13} \mathrm{C}$ NMR spectra, MS, and elemental analysis. Diazomethane 3 was not isolated in pure state and its content was estimated to be about $60 \%$ from the esterification with stearic acid.

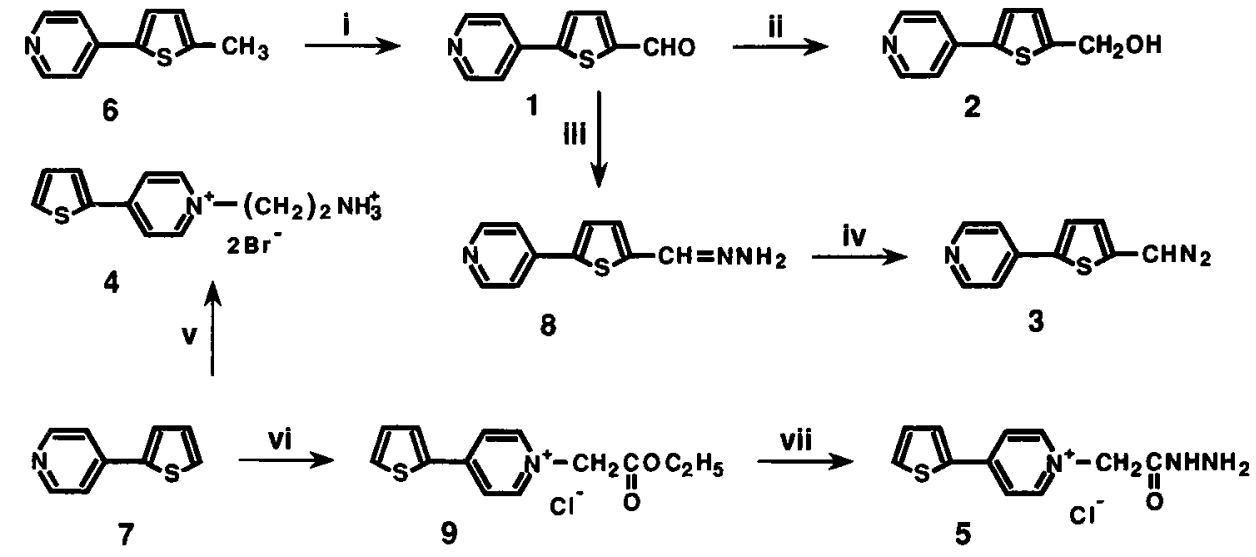

Scheme 1. i) $\mathrm{SeO}_{2},\left(\mathrm{CH}_{3}\right)_{2} \mathrm{C}_{6} \mathrm{H}_{4}$; ii) $\mathrm{NaBH} 3{ }_{3} \mathrm{CN}, \mathrm{HCl}-\mathrm{MeOH}(\mathrm{pH} 3)$; iii) $\mathrm{N}_{2} \mathrm{H}_{4} \bullet \mathrm{H}_{2} \mathrm{O}, \mathrm{MeOH}$; iv) $\mathrm{MnO}_{2}, \mathrm{CHCl}_{3}, \mathrm{KOH}-\mathrm{EtOH}$; v) $\mathrm{Br}\left(\mathrm{CH}_{2}\right)_{2} \mathrm{NH}_{2} \cdot \mathrm{HBr}, \mathrm{CH}_{3} \mathrm{CN}$; vi) $\mathrm{CH}_{2} \mathrm{ClCOOEt}$, EtOH; vii) $\mathrm{N}_{2} \mathrm{H}_{4} \cdot \mathrm{H}_{2} \mathrm{O}$, EtOH.

Determination of glycine with aldehyde 1 using CE. Our initial studies on the determination of primary alkylamines with 1 using HPLC were based on the combination of precolumn derivatization and postcolumn hydrolysis-detection of the original fluorescent reagent regenerated from the derivatives [6] as outlined in Scheme 2. Recently, we found that amino acids were determined by this method if a base catalyst was used in the precolumn reaction and that fluorescent

Previous work:

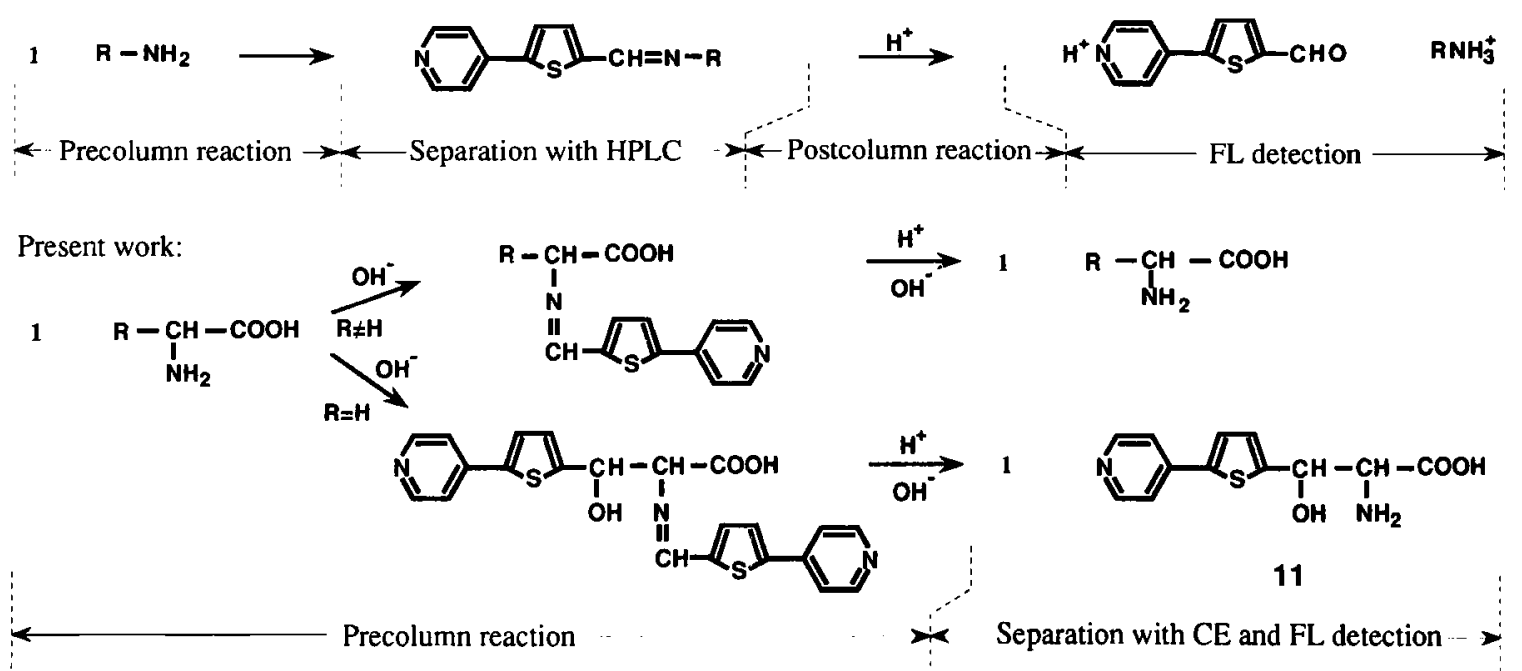

Scheme 2. Reaction procedures and flow chart of separation and detection systems.

$\beta$-[5-(4-pyridyl)-2-thienyl]serine(11) was synthesized from 1 and glycine(12)[8]. The present method, therefore, was designed to detect only 12 in various amino acids, in which the abovementioned combination of pre-and postcolumn reactions is used as a precolumn reaction and this new fluorescent amino acid separated from 1 by $C E$ was determined with fluorescence detector (Scheme 2); $0.25 \mathrm{ml}$ of ethanol containing both $5.0 \mu \mathrm{mol}$ of 1 and $1.0 \mu \mathrm{mol}$ of 10 , and $0.50 \mathrm{ml}$ of $0.2 \mathrm{M}\left(\mathrm{M}=\mathrm{mol} \mathrm{dm} \mathrm{dm}^{-3}\right)$ potassium hydroxide aqueous solution were added to $0.25 \mathrm{ml}$ of water or aqueous ethanol containing amino acids, the mixture was allowed to stand for $24 \mathrm{~h}$ at room temperature, and then $0.05 \mathrm{ml}$ of $0.5 \mathrm{M}$ hydrochloric acid was added to a $0.05-\mathrm{ml}$ portion of the mixture, followed by the addition of $0.01 \mathrm{ml}$ of $2.0 \mathrm{M}$ potassium hydroxide aqueous solution. Each $6 \mathrm{nl}$ of the solution was subjected to CE and determined by monitoring the fluorescence intensities. Figure 1 shows a typical electropherogram of 12 derivatized with 1 . The linear rang for 12 was $4.0 \times 10^{-5}-4.0 \times 10^{-3} \mathrm{M}$; the linear-correlation coefficient $w$ as 0.9984 and the detection 
$\operatorname{limits}(\mathrm{S} / \mathrm{N}=4) 4.0 \times 10^{-5} \mathrm{M}$. The coefficient of variation for $1.2 \mathrm{mM} 12$ solution $(\mathrm{n}=5)$ was $5.7 \%$. The following L-amino acids had no influence on the determination of 12 in the presence of a 20-fold excess: Ala, Asp, Cys, His, Met, Phe, Tyr, and Val.

We are still seeking more suitable derivatization and separation conditions because peak 3 in Fig. 1 occupied only $3 \%$ of the area estimated from standard 11, and because the peak included that of a by-product derived from 12 and 1 .

Determination of carboxylic acids with 2 or 3 using HPLC. Recently, we reported that both reagents 2 and 3 reacted with fatty acids to produce the corresponding esters (IFS (Intrinsic fluorescence sensitivity $=\varepsilon \cdot \phi_{\mathrm{f}} / \mathrm{W}_{1 / 2}$ ) $=0.81-2.96$ ) which were separated with ODS column $[4,7]$ and that the latter reagent also reacted with bile acids without heating and a condensing reagent to produce fluorescent esters which were separated with ODS column [7]. Unsaturated fatty acids(13) and glycineconjugated bile acids $(14)$ were derivatized with 3 and the produced esters were separated with ODS column as shown in Fig. 2; $0.2 \mathrm{ml}$ of 4 mM 3 methanol solution was added to $0.2 \mathrm{ml}$ of methanol containing carboxylic acids, allow-

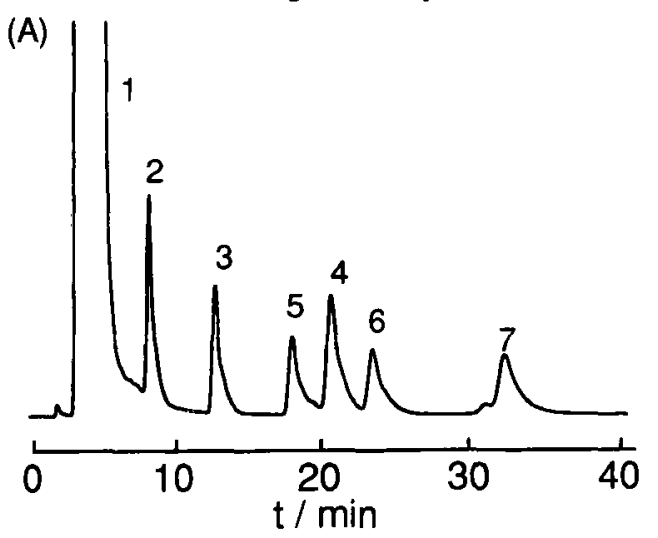

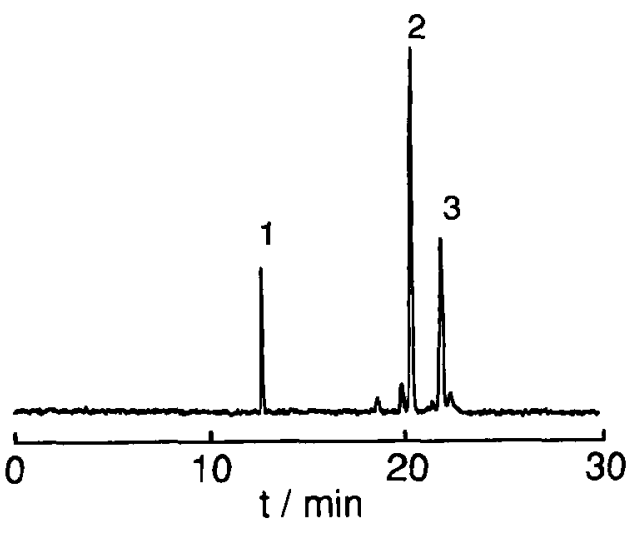

Fig. 1 Electropherogram of a sample prepared by the derivatization of $0.75 \mu \mathrm{mol}$ of 12 with $5.0 \mu \mathrm{mol}$ of 1 : (1) 10, (2)1, and (3)11. The area under peak 3 corresponds to $2.0 \mathrm{pmol}$ of 12 . Capillary inside diameter, $50 \mu \mathrm{m}$, length $100 \mathrm{~cm}(75 \mathrm{~cm}$ to the detector); applied voltage, $20 \mathrm{kV}(20 \mu \mathrm{A})$; electrolyte, 10 $\left.\mathrm{mM} \mathrm{Na} 2 \mathrm{HPO}_{4}: 40 \mathrm{mM} \mathrm{NaH} 2 \mathrm{PO}_{4}=1: 1 \mathrm{v} / \mathrm{v}\right)$; gravity injection from $30 \mathrm{~cm}$ for $10 \mathrm{~s}(6 \mathrm{nl})$; detector, Shimadzu RF-535 fluorescence HPLC monitor with a homemade capillary holder, $\lambda_{\mathrm{ex}}=299 \mathrm{~nm}, \lambda_{\mathrm{em}}=366 \mathrm{~nm}$.

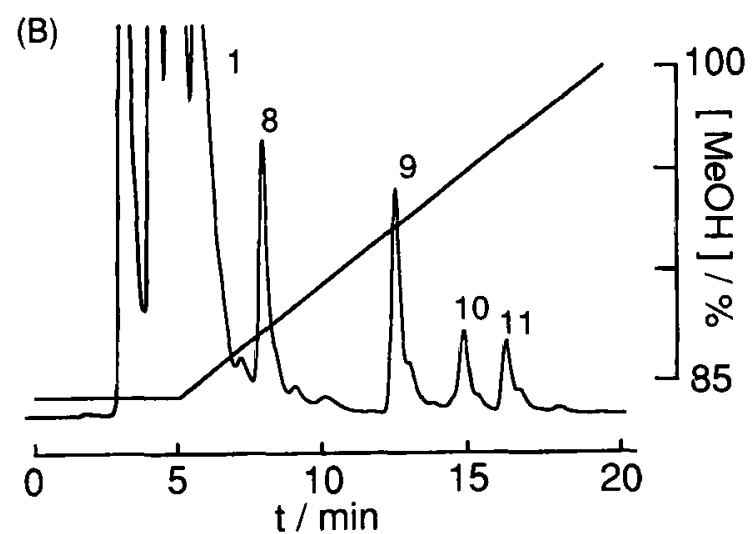

Fig. 2 Chromatograms of 5-(4-pyridyl)-2-thiophenemethyl esters of (A)13 and (B)14: (1)3, (2) 10-undecenoic (13a), (3)dodecanoic, (4)cis-9-hexadecenoic(13b), (5)cis-9-octadecenoic (13c), (6)cis, cis-9,12-octadecadienoic(13d), (7)cis, cis, cis-6,9,12-octadecatrienoic(13e), (8)glycocholic(14a), (9)glycodeoxycholic(14b), (10)cholic, and (11)hyodeoxycholic acids. Column, $150 \times 6 \mathrm{~mm}$ i.d. Shim-pack CLC-ODS; eluent, (A) $95 \%$ methanol, (B) $83-100 \%$ methanol, $1.0 \mathrm{ml} \mathrm{min-1;} \mathrm{sample} \mathrm{size,} 1 \mu \mathrm{l}(100 \mathrm{pmol})$; detector, Shimadzu RF $-535, \lambda_{\mathrm{ex}}=300$ $\mathrm{nm}, \lambda_{\mathrm{em}}=360 \mathrm{~nm}$.

ed to stand for $3 \mathrm{~h}$, and each $1 \mu \mathrm{l}$ of the solution was subjected to HPLC. The linear ranges for 13 and 14 were from $0.5 \mathrm{pmol}$ to $100 \mathrm{pmol}$ and from $0.15-1.50 \mathrm{pmol}$ to $150 \mathrm{pmol}$, respectively; the linear-correlation coefficients were $0.9929-0.9983$ and $0.9934-0.9964$ and the detection limits $(\mathrm{S} / \mathrm{N}=2)$ were $0.5 \mathrm{pmol}$ and $30-150 \mathrm{fmol}$. The coefficients of variation for $1.0 \times 10^{-5} \mathrm{M} 13$ and 14 solutions $(n=6)$ were $1.7-3.8 \%$ and $2.3-4.4 \%$. Alcohol 2 reacted with 13 under the conditions described previously[4], as well as 3 , to form the corresponding esters which were separated with ODS column. Consequently, both reagents 2 and 3 were available for the determinatioin of 13. The methods presented here were more excellent in detection limits and linear ranges than those reported previously[2].

Determination of carboxylic acids with 4 using $C E$. Since reagent 4 reacted with saturated fatty acids in the presence of dicyclohexylcarbodiimide(15) at $40^{\circ} \mathrm{C}$ to produce the corresponding esters which are separated using CE with a lower detection limit of $1.0 \times 10^{-6} \mathrm{M}(6 \mathrm{fmol})$ and plate number of about $1 \times 10^{5 / 75} \mathrm{~cm}[5,9]$, some unsaturated fatty acids $(13 \mathrm{a}-13 \mathrm{f})$ were examined; $0.1 \mathrm{ml}$ of DMF containing $0.5-500 \mathrm{nmol}$ of carboxylic acids and $0.10 \mathrm{ml}$ of $2.0 \mathrm{mM} 3 \mathrm{DMF}$ solution were added to a mixture of $4(3.5 \mathrm{mg}, 9.0 \mathrm{mmol}), 15(31 \mathrm{mg}, 0.15 \mathrm{~mol})$ and 4 -dimethylaminopyridine $(3.6 \mathrm{mg}, 30 \mathrm{mmol})$, diluted to $0.5 \mathrm{ml}$ with DMF, heated with stirring at $40^{\circ} \mathrm{C}$ for 2 
$\mathrm{h}$, and then cooled. Each $6 \mathrm{nl}$ of the solution was subjected to $C E$, and determined by monitoring the fluorescence intensities. A typical electropherogram is shown in Fig. 3. All the linear ranges for $13 \mathbf{a}-\mathbf{c}$ and $13 \mathbf{f}$ were $1.0 \times 10^{-3}-1.0 \times 10^{-5} \mathrm{M}$ (solutions siphoned); the linear-correlation coefficients were 0.9985 0.9999 and the detection $\operatorname{limits}(\mathrm{S} / \mathrm{N}=2)$ were $5.0 \times 10^{-6}-6.4 \times 10^{-6} \mathrm{M}$. The coefficients of variation for $5.0 \times 10^{-4} \mathrm{M}$ solutions $(n=7)$ were $2.5-6.5 \%$. Although no description on the determination of 13 by $C E$ has been made, the present results were superior in linear ranges and plate number and similar in the lower detection limits to those for short-chain carboxylic acids reported by Zare, et al. [3].

Determination of aldehydes and ketones with fluorescent Girard reagent 5 using CE. Since the lower detection limits of carboxylic acids derivatized with 4 exceeded our expectation, reagent 5 containing the same fluorophore was prepared; its IFS value was 0.27 , which was close to that of $4(0.30)$. One $\mathrm{ml}$ of methanol containing $4.0 \mu \mathrm{mol}$ of 5 was added to $1.0 \mathrm{ml}$ of methanol containing each $0.60 \mu \mathrm{mol}$ of benz-(16a), 4-anis-(16 b), and 4 isopropylbenzaldehyde $(16 \mathrm{c})$, heated with stirring at $60^{\circ} \mathrm{C}$ for $0.5 \mathrm{~h}$, and then cooled. Each $6 \mathrm{nl}$ of the solution was subjected to CE (Fig. 4). Although the optimum derivatization and separation conditions were not sought, the peak height and area of the derivatized aldehydes were close to those of the esters in Fig. 3. Their aetection l1mils and linear ranges may therefore be close to those of the acids. Heptanal, aceto-. propio-, and benzophenone, etc. were also derivatized and determined.

Since the sensitivities of the reagents 4 and 5 prepared were better than those we expected, new derivatization reagents containing 5-(1alkyl-4-pyridinio)-5' -(4-pyridinio)-2,2' -bithienyl in place of 4-(2-thienyl)pyridine is being prepared. Their IFS values were estimated to be 9.4[1] and the detection limits 0.2 fmol.

We would like to thank Mr. Kei-ichiro Ohnishi for obtaining the mass spectra, and SHELL KAGAKU K. K. for kindly supplying a sample of 2-methylthiophene. The present work was partially supported by the Aid of Doshisha University's Research Promotion Fund(1991).

\section{REFERENCES}

1. R. Nakajima, H. Iida and T. Hara, Bull. Chem. Soc. Jpn., 63, 636(1990).

2. S. Kamada, M. Maeda and A. Tsuji, J. Chromatogr., 272, 29(1983).

3. X. Huang, J. A. Luckey, M. J. Gordon and R. N. Zare, Anal. Chem., 61, 766(1989).

4. R. Nakajima, K. Shimada, Y. Fujii, A. Yamamoto and T. Hara, Bull. Chem. Soc. Jpn., in press.

5. R. Nakajima, H. Kamiuchi and T. Hara, Proceedings of 52nd Symposium on Analytical Chemistry, Obihiro, May 1991, p. 371.

6. R. Nakajima, A. Yamamoto and T. Hara, Bull. Chem. Soc. Jpn., 63, 1968(1990).

7. R. Nakajima, K. Shimada and T. Hara, Proceedings of 52nd Symposium on Analytical Chemistry, Obihiro, May 1991, p. 273.

8. R. Nakajima, E. Nakamoto and T. Hara, unpublished results.

9. The values of the detection limit were obtained under the more suitable separation conditions different from that described in ref. 6 